\title{
The Management of Constipation in Palliative Care
}

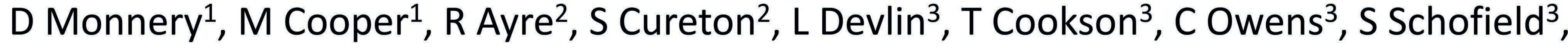 \\ G Sudworth ${ }^{3}$, C Hyland ${ }^{3}$, L Edmunds ${ }^{1}, E$ Waters $^{1}$ \& A Scott ${ }^{4}$.
}

${ }^{1}$ Clatterbridge Cancer Centre, ${ }^{2}$ Bridgewater Community Trust, ${ }^{3}$ Willowbrook Hospice, ${ }^{4}$ Marie Curie Hospice, Liverpool.
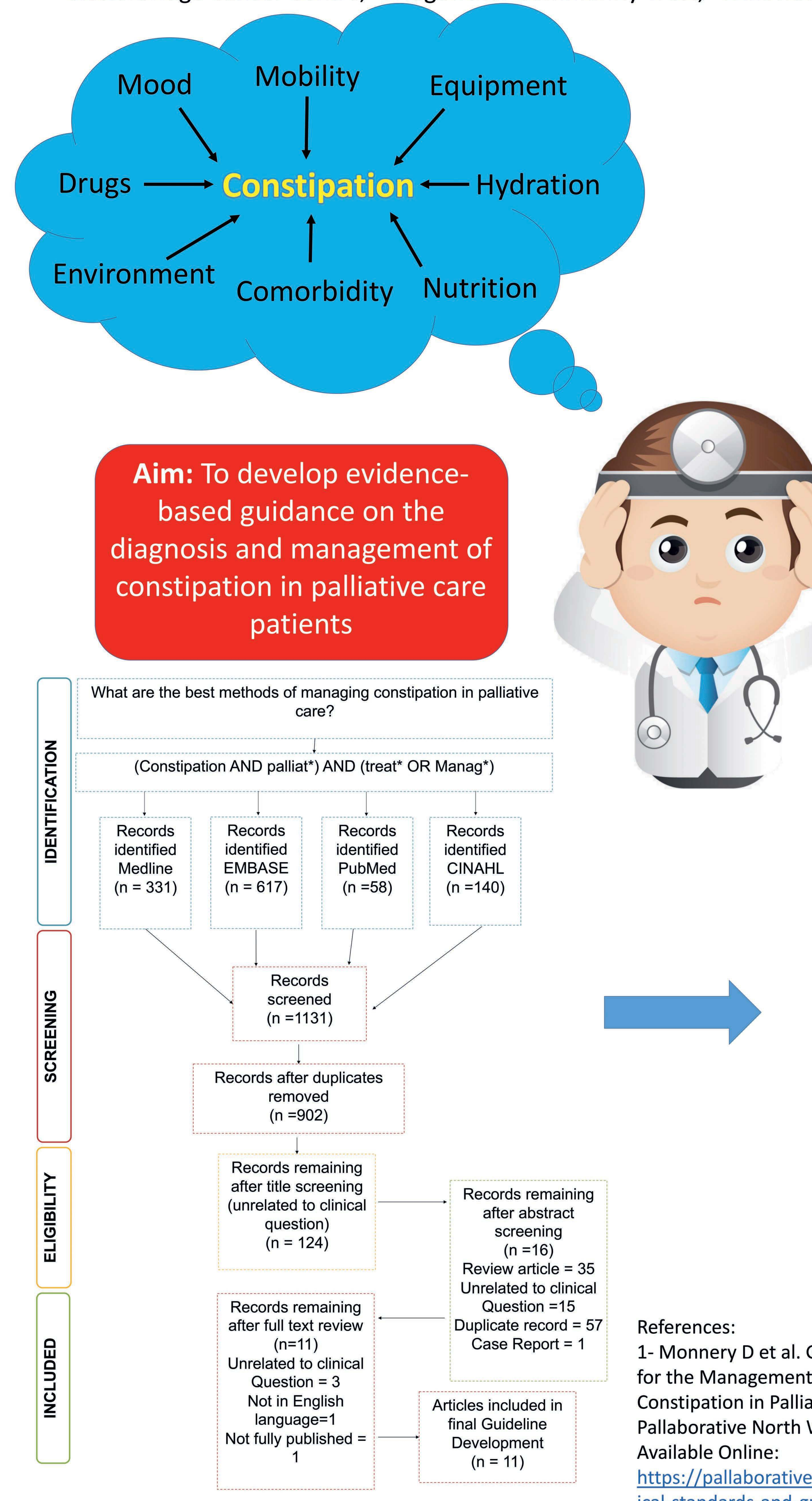

Constipation affects $90 \%$ of my patients but each person has a different combination of causative factors! Its impossible to choose a laxative that suits all causes, so I've resorted to using trial and error in my choice of laxatives Aim: To develop evidenceiagnosis and management of patients 